\title{
TITLE:
}

\section{Palmtop EPMA by Electric Battery}

\section{$\operatorname{AUTHOR}(\mathrm{S})$ :}

Imashuku, Susumu; Imanishi, Akira; Kawai, Jun

\section{CITATION:}

Imashuku, Susumu ...[et al]. Palmtop EPMA by Electric Battery. AIP Conference Proceedings: X-Ray Optics and Microanalysis 2012, 1437: 29-31

\section{ISSUE DATE:}

2012-05-17

URL:

http://hdl.handle.net/2433/187972

\section{RIGHT:}

(C) 2012 American Institute of Physics. This article may be downloaded for personal use only. Any other use requires prior permission of the author and the American Institute of Physics. 


\title{
Palmtop EPMA by Electric Battery
}

\author{
Susumu Imashuku, Akira Imanishi, and Jun Kawai \\ Department of Materials Science and Engineering, Kyoto University, Sakyo, Kyoto 606-8501, Japan
}

\begin{abstract}
The measurement pressure of a palmtop electron probe X-ray microanalyzer (EPMA) we previously reported was reduced using stainless steel vacuum flanges for the chamber instead of a borosilicate glass tube. The improved palmtop EPMA could reach the measurement pressure of $1 \mathrm{~Pa}$ in 5 minutes. The time was more than twice shorter than that to reach the measurement pressure of $5 \mathrm{~Pa}$ with the palmtop EPMA we previously reported. Titanium, copper $\mathrm{K}$ lines and silver L $\alpha$ line were observed during 90 seconds measurement in addition to chromium, iron, and nickel $\mathrm{K}$ lines when titanium, copper, and silver plates were placed on the carbon sample stage. Chromium, iron, and nickel $\mathrm{K}$ lines came from stainless steel, and copper K lines came from copper rod and copper plate placed on the sample stage. The improved palmtop EPMA can analyze metals except for chromium, iron, nickel, and small amount of copper in 90 seconds.
\end{abstract}

Keywords: Palmtop EPMA, Pyroelectric crystal PACS: $07.05 . \mathrm{Fb}$

\section{INTRODUCTION}

When a temperature change under a vacuum condition is applied to a pyroelectric crystal such as lithium tantarate $\left(\mathrm{LiTaO}_{3}\right)$ and lithium niobate $\left(\mathrm{LiNbO}_{3}\right)$, an electric field is produced due to uncompensated charge on the surface of the pyroelectric crystal. As a result, quite small amounts of suspended electrons and ions in the condition are accelerated by the electric field. Applying this property, an X-ray generator using $\mathrm{CsNO}_{3}$ single crystal cooled and heated by a Peltier device was invented by Brownridge ${ }^{1}$ and commercially available from Amptek. ${ }^{2}$ We have fabricated an in-house portable X-ray tube which consisted of paired-crystal of $\mathrm{LiTaO}_{3}$ as shown in Figure 1 (a). The accelerated electrons in low vacuum excited strong copper and zinc characteristic X-rays from a brass piece placed on the $\mathrm{LaTiO}_{3}$ crystal $^{3}$ and we could perform EPMA analysis (electron excited X-ray emission) of the brass piece using electric batteries. Then, we presented an EPMA with a palmtop size chamber including the electron source and the sample stage using a $\mathrm{LiTaO}_{3}$ crystal as an electron source. ${ }^{4}$ The EPMA consisted of $\mathrm{LiTaO}_{3}$ crystal, brass sample stage, rotary pump, vacuum joints, borosilicate glass tube, and copper rods. It took more than 10 minutes for the palmtop EPMA to reach the measurement pressure of $5 \mathrm{~Pa}$. In the present study, we tried to reduce the measurement pressure of the palmtop EPMA by changing the chamber from the borosilicate glass tube to stainless steel vacuum flanges.

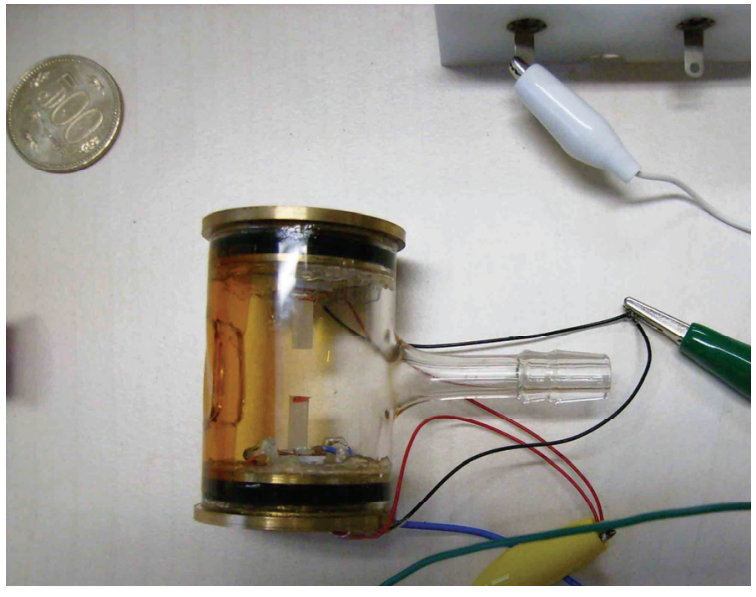

FIGURE 1. In-house made pyroelectric X-ray generator.

\section{EXPERIMENTAL}

The apparatus used on the present study is shown in Figure 2. A single crystal of $\mathrm{LiTaO}_{3}$ (Shin-Etsu Chemical) was used as an electron source, and the photo of the electron source is shown in Figure 3 (a). The size of the $\mathrm{LiTaO}_{3}$ crystal was $3 \mathrm{~mm} \times 3 \mathrm{~mm}$ in $\mathrm{x}$ $y$ plane and $5 \mathrm{~mm}$ in $\mathrm{z}$-axis. $+\mathrm{z}$ plane of the $\mathrm{LiTaO}_{3}$ crystal was attached on a Peltier device with silver paste. Silver paste was chosen as an adhesive agent due to its high thermal and electrical conductivity. The other face of the Peltier device was attached on a copper rod with silver paste. The copper rod was connected to a rotary pump (G-10DA, ULVAC) through a vacuum joint. A sample stage was attached on anther copper rod with silver paste, and a picture of the sample stage is shown in Figure 3 (b). The sample 
stage had $45^{\circ}$ tilt angle and consisted of carbon. Samples were set on the sample stage with a carbon tape. Stainless steel vacuum flanges were used for a chamber including the electron source and the sample stage. The two copper rods were connected with a copper wire in order to keep the electric potential of the sample stage the same as $+\mathrm{z}$ plane of the $\mathrm{LiTaO}_{3}$ crystal. The center of the chamber had a through-hole whose diameter was $10 \mathrm{~mm}$. A polyimide tape (Kapton tape) was put on the through-hole. Si-PIN (X123, Amptek Inc.) was set towards the through-hole as shown in Figure 2 (b). The Peltier device was connected to $3 \mathrm{~V}$ battery and heated the $\mathrm{LiTaO}_{3}$ crystal for 2 minutes. Then, the $\mathrm{LiTaO}_{3}$ was cooled by applying power to the Peltier device and measured Xray spectra for 90 seconds. Pressure of the chamber was monitored with Pirani gauge during the measurement. Titanium (99.5\%), copper $(99.99 \%)$ 、 silver $(99.98 \%)$ plates were used as samples. The size of the three samples was $2 \mathrm{~mm} \times 5 \mathrm{~mm}$ in width.
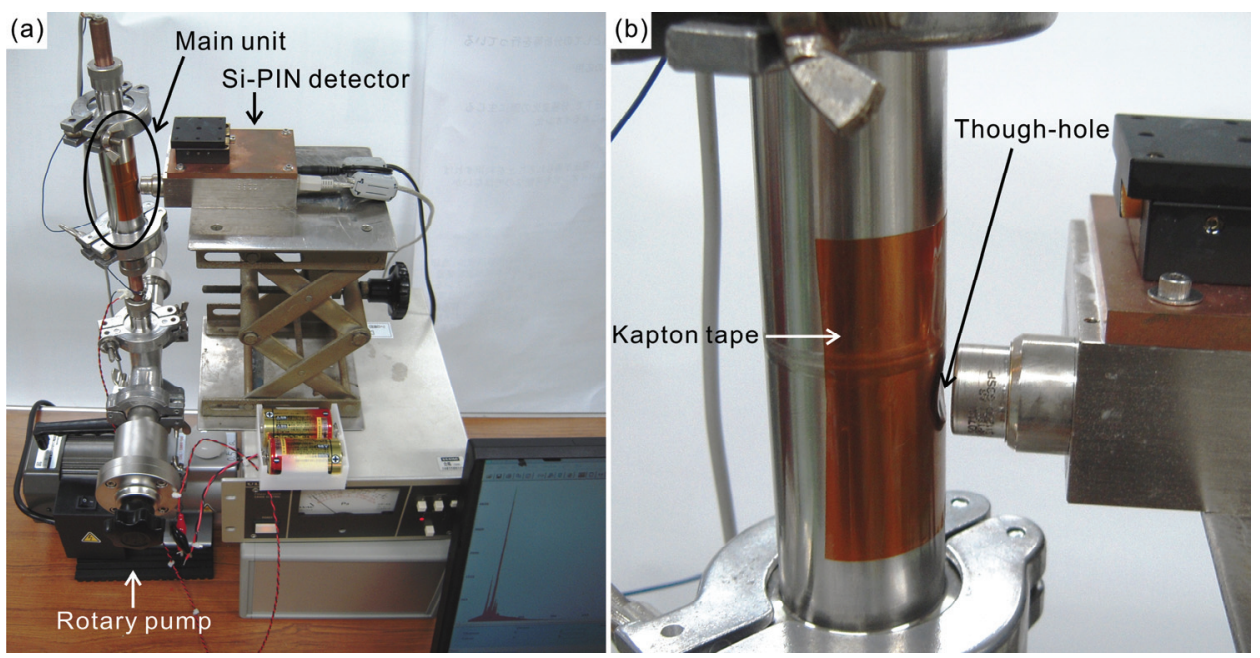

FIGURE 2. (a) Palmtop EPMA designed in the present study and (b) Main unit of the palmtop EPMA.
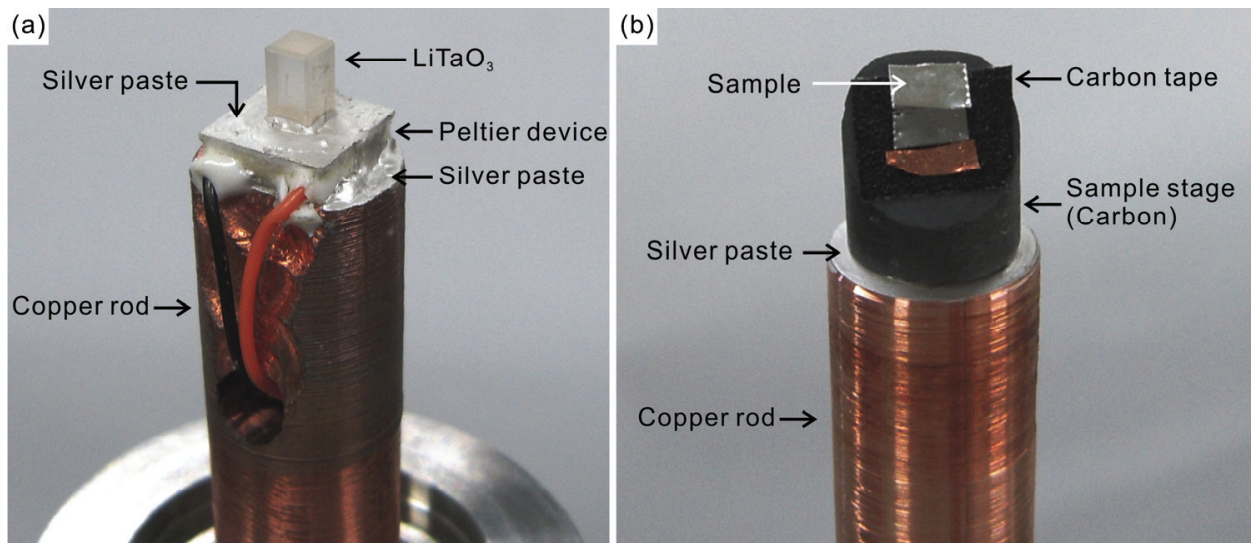

FIGURE 3. (a) Electron source and (b) sample stage of the palmtop EPMA designed in the present study.

\section{RESULTS AND DISCUSSION}

The palmtop EPMA we designed in the present study can reach the measurement pressure of $1 \mathrm{~Pa}$ in 5 minutes. Figure 4 (a) shows an EDX spectrum without placing samples on the sample stage with the improved palmtop EPMA. Chromium, iron, nickel, and copper $\mathrm{K}$ lines were observed. Chromium, iron, and nickel came from the stainless steel vacuum flanges. Copper originated from the copper rod placed underneath the sample stage. High intensities of Xrays including continuous X-rays were obtained in 90 seconds measurement. Elemental analysis of titanium, 
copper, and silver plates were performed with the improved palmtop EPMA and the EDX spectrum is shown in Figure 4 (b). Weak silver L $\alpha$ line and strong titanium and copper $\mathrm{K}$ lines were observed in addition to chromium, iron, and nickel $\mathrm{K}$ lines. The result shows that the improved palmtop EPMA can analyze metal plates except for chromium, iron, nickel, and small amount of copper in 90 seconds measurement.
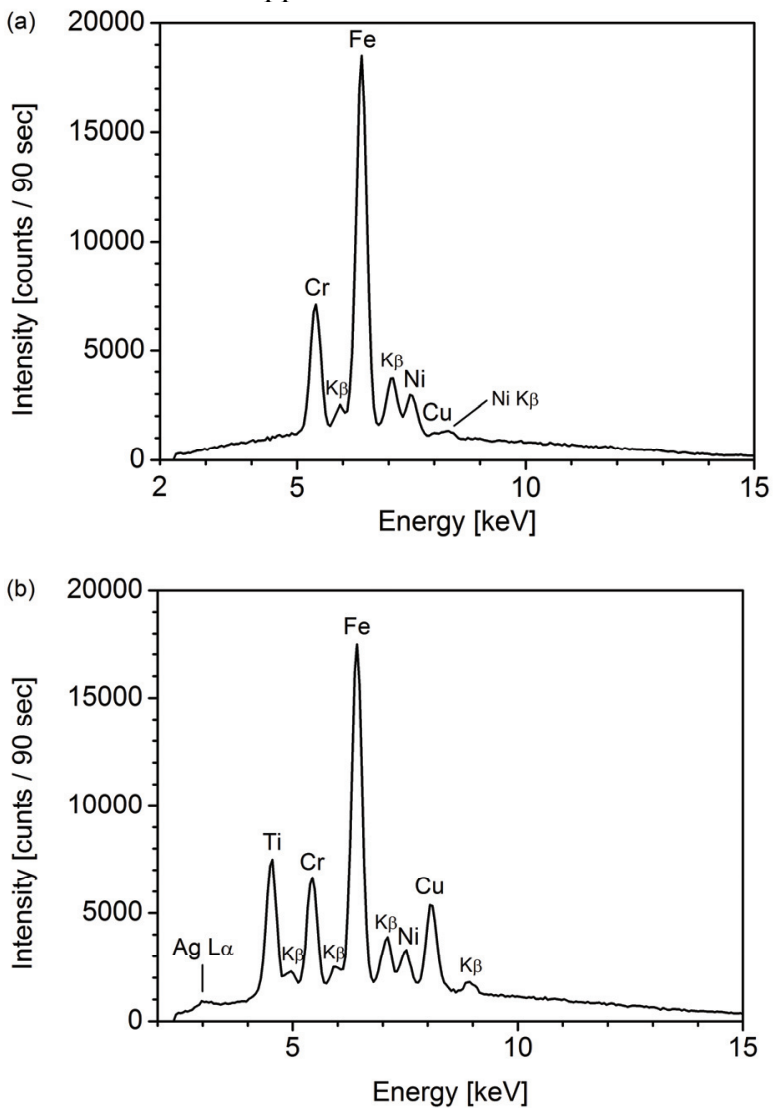

FIGURE 4. EDX spectra (a) without placing samples on the sample stage and (b) of titanium, copper, and silver plates with the improved palmtop EPMA.

\section{CONCLUSIONS}

We reduced the measurement pressure of a palmtop electron probe X-ray microanalyzer (EPMA) we previously reported from 5 to $1 \mathrm{~Pa}$ using stainless steel vacuum flanges for the chamber instead of a borosilicate glass tube. The improved palmtop EPMA could reach measurement pressure of $1 \mathrm{~Pa}$ in 5 minutes. The time was more than twice shorter than that to reach the measurement pressure of $5 \mathrm{~Pa}$ with the palmtop EPMA we previously reported. When titanium and copper plates were placed on the carbon sample stage, titanium and copper $\mathrm{K}$ lines were clearly observed during 90 seconds measurement in addition to chromium, iron, and nickel $\mathrm{K}$ lines which came from stainless steel vacuum flanges in the chamber. The palm-top EPMA we designed in the present study can analyze metals except for chromium, iron, nickel, and small amount of copper in 90 seconds.

\section{ACKNOWLEDGMENTS}

The present study was supported by the Asahi Glass Foundation. A part of the present study was also financially supported by the Murata Science Foundation. We also express our deep thanks to ShinEtsu Chemical Co., Ltd. for the supply of single crystal of lithium tantalate.

\section{REFERENCES}

1. J.D. Brownridge, Nature 358, 287-288 (1992).

2. http://www.amptek.com/

3. E. Hiro, T. Yamamoto, and J. Kawai, Adv. X-ray. Chem. Anal., Japan 41, 195-200 (2010).

4. S. Imashuku, A. Imanishi, and J. Kawai, Anal. Chem. 83, 8363-8365 (2011). 
Copyright of AIP Conference Proceedings is the property of American Institute of Physics and its content may not be copied or emailed to multiple sites or posted to a listserv without the copyright holder's express written permission. However, users may print, download, or email articles for individual use. 